\title{
Demodicose associada à Esporotricose e Pediculose em gato co-infectado por FIV/FeLV
}

\author{
Demodicosis associated with Sporotrichosis and Pediculosis in a positive FIV/FeLV cat
}

\author{
Sandro Antonio Pereira ${ }^{1}$, Tânia Maria Pacheco Schubach ${ }^{1}$, Fabiano Borges Figueiredo ${ }^{1}$, Luiz Rodrigo \\ Paes Leme ${ }^{1 *}$, Isabele Barbieri dos Santos ${ }^{1 *}$, Thais Okamoto ${ }^{1}$, Tulia Cuzzi ${ }^{2}$, Rosani dos Santos Reis ${ }^{3}$ \& \\ Armando Schubach ${ }^{1}$
}

\begin{abstract}
RESUMO
Demodicose é a ectoparasitose causada por ácaros do gênero Demodex e a ocorrência no gato é rara. Os sinais clínicos da doença felina são inespecíficos e os diagnósticos diferenciais são extensos. A forma generalizada geralmente está associada à infecção pelos vírus da Imunodeficiência Felina (FIV) ou da Leucemia Felina (FeLV). Esporotricose é uma micose causada pelo Sporothrix schenckii. Gatos apresentam elevada susceptibilidade à doença e podem desempenhar importante papel na sua transmissão. Pediculose é a infestação por piolhos que nos gatos é comumente determinada pela espécie Felicola subrostratus. É relatado um caso de demodicose associada a esporotricose e pediculose, em um gato co-infectado por FIV/ FeLV, com 8 anos de idade, que apresentou na primeira avaliação escoriações e úlceras cutâneas, alopecia e prurido cervical, descamação no dorso, espirros e adenite generalizada. Inicialmente, foram diagnosticadas esporotricose e pediculose, através da demonstração dos respectivos agentes etiológicos, e a infecção pelo FIV e FeLV detectada no soro pelo ensaio imunoenzimático. Instituiu-se tratamento com itraconazol 50mg diariamente por via oral e imidacloprid tópico. Após 30 dias, persistia o prurido associado a eritema generalizado e presença de Felicola subrostratus nos pelos. Após nova investigação, detectouse a presença de Demodex cati no exame direto de raspado de pele e na histopatologia. Instituiu-se terapia com ivermectina 0,4 $\mathrm{mg} / \mathrm{kg}$ diariamente por via oral em associação ao itraconazol e imidacloprid. Após 4 meses de tratamento irregular houve abandono. Decorridos 16 meses, o paciente retornou pela última vez com cura clínica da pediculose, demodicose e esporotricose. A rara associação de diferentes infecções dificultou a realização do diagnóstico definitivo.
\end{abstract}

Descritores: demodicose, esporotricose, pediculose, FIV, FeLV, gatos.

\section{ABSTRACT}

Demodicosis in an ectoparasitic disease caused by mites of the genus Demodex which rarely occurs in cats. The clinical signs of feline disease are nonspecific and there are extensive differential diagnoses. The generalized form is usually associated with infection with Feline Immunodeficiency virus (FIV) or Feline Leukemia virus (FeLV). Sporotrichosis is a mycosis caused by Sporothrix schenckii to which cats are highly susceptible, possibly playing an important role in disease transmission. Pediculosis is infestation with lice which in cats is usually determined by the species Felicola subrostratus. We report here a case of demodicosis associated with sporotrichosis and pediculosis involving an 8-year-old cat coinfected with FIV/FeLV. At first evaluation, the animal presented excoriations and skin ulcers, alopecia and cervical pruritus, dorsal desquamation, sneezing, and generalized adenitis. Sporotrichosis and pediculosis were first diagnosed by the demonstration of the respective etiologic agents, and infection with FIV and FeLV was detected in serum by an immunoenzymatic assay. Treatment with itraconazole, $50 \mathrm{mg}$ daily by the oral route, and topical imidacloprid was started. After 30 days, pruritus persisted, associated with generalized erythema and the presence of Felicola subrostratus in the hair. After a new investigation, Demodex cati was detected by direct examination of a skin scraping and by histopathology. Oral treatment with ivermectin, $0.4 \mathrm{mg} / \mathrm{kg}$ daily, was started in combination with itraconazole and imidacloprid. Treatment was applied irregularly for 4 months and then abandoned. After 16 months, the patient returned for the last time, with clinical cure of pediculosis, demodicosis and sporotrichosis. The rare combination of different infections impaired treatment.

Key words: demodicosis, sporotrichosis, pediculosis, FIV, FeLV, cats. 


\section{INTRODUÇÃO}

A demodicose é uma doença cutânea parasitária que acomete vários animais domésticos e selvagens, causada por ácaros do gênero Demodex [2]. A doença no gato é rara e as espécies causadoras são Demodex cati, que ocasiona a demodicose folicular, e D. gatoi responsável pela demodicose superficial [7]. Existe o relato de uma terceira espécie ainda não identificada [5]. Clinicamente a demodicose pode se apresentar nas formas localizada ou generalizada, sendo que os principais sinais são alopecia, descamação e eritema [6]. Nos casos onde o agente causador é $D$. gatoi o prurido é um importante sinal clínico [11]. A forma generalizada desta ectoparasitose no felino normalmente está associada a uma doença sistêmica concorrente, tais como infecções pelos vírus da imunodeficiência felina (FIV) [2] e da leucemia felina (FeLV) [4], endocrinopatias [6], doenças imunomediadas [11] e terapias com esteróides [7].

A esporotricose é uma micose causada pelo fungo dimórfico Sporothrix schenckii, que pode acometer várias espécies animais incluindo o homem [8]. Nos gatos essa doença costuma acometer machos inteiros em idade reprodutiva; a forma de contágio mais freqüente é através de brigas com outros gatos; apresentando um amplo espectro clínico, variando desde uma infecção subclínica até a forma sistêmica fatal [9]. No Rio de Janeiro, vem sendo registrada uma epidemia de esporotricose na qual os gatos têm sido incriminados como transmissores da doença a seres humanos, cães e outros gatos [1,10].

A infestação por piolhos é denominada pediculose e nos gatos o agente etiológico comumente incriminado é a espécie Felicola subrostratus. Clinicamente pode ser assintomática ou determinar prurido intenso, com dermatite e perda de pelos no dorso, em alguns casos lembrando a dermatite miliar ou hipersensibilidade a picada de pulgas [11].

O objetivo desta publicação é relatar um caso raro de demodicose associada a esporotricose e pediculose em um gato co-infectado pelo FIV e FeLV.

\section{RELATO DE CASO}

Um gato procedente do município do Rio de Janeiro, com hábito de ir à rua e brigar com outros gatos, foi encaminhado para atendimento clínico no Serviço de Zoonoses do Instituto de Pesquisa Clínica Evandro Chagas (IPEC) - FIOCRUZ, Rio de Janeiro.
Durante o exame clínico observou-se o gato, sem raça definida, macho, inteiro, 8 anos, pesando 4,1 $\mathrm{kg}$, em bom estado geral, com escoriações e alopecia nas regiões cefálica e cervical (Figura 1), úlceras no membro anterior esquerdo (Figura 2), acentuada queda de pelos, descamação furfurácea no dorso, prurido, espirros, adenite generalizada e presença de ectoparasitos. Foram realizados exame clínico, hemograma completo, ensaio imunoenzimático no soro para detecção de FIV/ FeLV, raspados de pele e pelos para exames parasitológico e micológico, além de biópsias de pele para cultura micológica e histopatologia [11].

$\mathrm{O}$ hemograma indicou anemia e leucocitose eosinofílica. Os exames para FIV e FeLV foram positivos. No raspado de pele e pelos foram visualizados piolhos da espécie Felicola subrostratus. S. schenckii foi isolado a partir do cultivo do fragmento de pele e ao exame histopatológico foram observados numerosos elementos arredondados corados pelo PAS.

Foi recomendado o isolamento do paciente e iniciado tratamento com imidacloprid tópico em dose única e itraconazol 50mg a cada 24 horas por via oral.

Após 30 dias, o animal compareceu à revisão apresentando eritema cutâneo generalizado (Figura 3), prurido e presença de Felicola subrostratus nos pelos. Manteve-se o tratamento com itraconazol, recomendou-se uma nova aplicação de imidacloprid, foi reforçada a importância do isolamento e marcada revisão em 4 semanas. No retorno, os exames histopatológico de nova biópsia cutânea da cernelha e parasitológico de novo raspado de pele da região dorsal evidenciaram a presença de ácaros Demodex cati (Figura 4). O paciente não compareceu a revisão solicitada, sendo reavaliado 12 semanas depois, quando em associação à terapia antifúngica, prescreveu-se ivermectina $0,4 \mathrm{mg} / \mathrm{kg}$ a cada 24 horas por via oral.

Os tratamentos antifúngico e antiparasitário seguiram irregularmente durante quatro meses, havendo então o abandono do tratamento.

Cinco meses após, o gato retornou com uma nova lesão ulcerada na bolsa escrotal, com 30 dias de evolução. Na ocasião, o animal encontrava-se em bom estado geral e apresentava cicatrizes atróficas na face, nariz e nas regiões cefálica e cervical.

O exame parasitológico de pele, realizado nessa avaliação, não evidenciou presença de ácaros; entretanto o exame micológico da secreção da lesão ulcerada na bolsa escrotal resultou no reisolamento de S. schenckii. 
Pereira S.A., Schubach T.M .P., Figueiredo F.B., Paes Leme L.R., Santos I.B., Okamoto T., Cuzzi T., Reis R.S. \& Schubach A. 2005. Demodicose associada à Esporotricose e Pediculose em gato... Acta Scientiae Veterinariae. 33: 75-78.

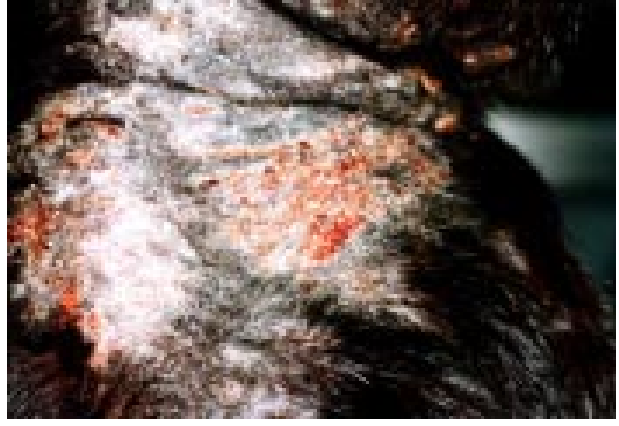

Figura 1. Escoriações, alopecia e eritema nas regiões cefálica e cervical do gato.

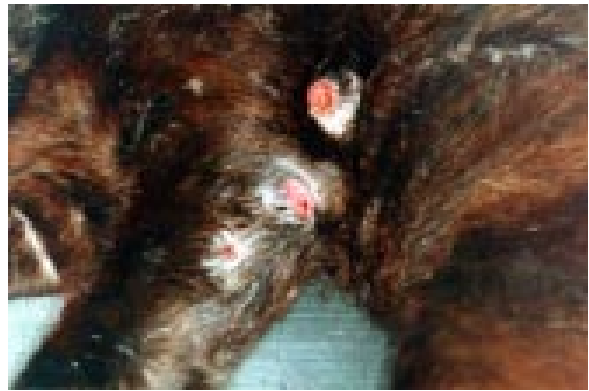

Figura 2. Lesões cutâneas ulceradas dispostas linearmente no membro anterior esquerdo do gato causadas por Sporothrix schenckii.

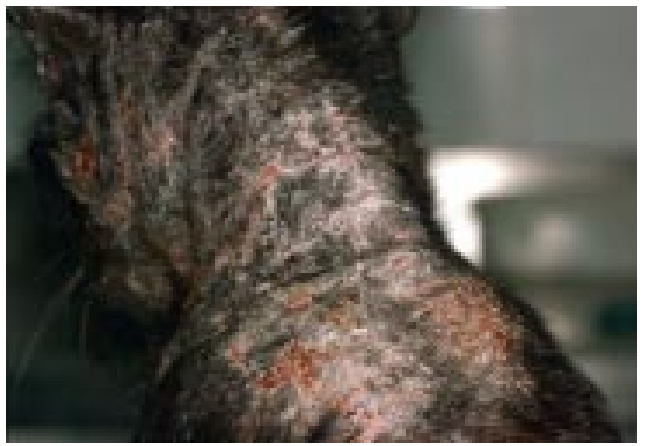

Figura 3. Eritema cutâneo intenso nas regiões cefálica e cervical dorsais do gato determinado por Demodex cati.

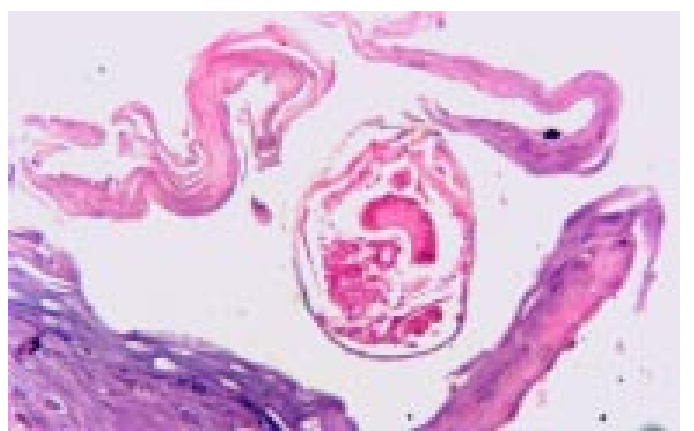

Figura 4. Demodicose felina: Microfotografia demonstrando segmentos de ácaro presentes na ceratina superficial. Corado pelo H\&E (40X).
Após algumas tentativas de acompanhamento, houve novamente abandono do tratamento. O responsável somente retornou com o paciente após 3 meses para avaliação, alegando que animal continuava tendo acesso a rua, brigando com outros gatos e fazendo uso irregular de medicação antifúngica. Durante o exame clínico não foram observadas lesões cutâneas, exceto as cicatrizes anteriormente citadas, e o paciente encontrava-se em bom estado geral. $\mathrm{O}$ tratamento antifúngico foi prescrito por 30 dias e foram realizados novos raspados de pele para exame parasitológico, cujo resultado foi negativo.

Somente após 4 meses o paciente retornou para revisão. O responsável informou que continuava a administrar o itraconazol e que o paciente eventualmente saía a rua e brigava com outros gatos. Neste momento não foram observadas lesões cutâneas ativas e sinais respiratórios (Figura 5), sendo procedida a coleta das secreções nasais e orais com auxílio de swabs estéreis para cultivo fúngico. Os resultados foram negativos e o paciente recebeu alta.

\section{DISCUSSÃO E CONCLUSÕES}

Num primeiro momento diagnosticou-se esporotricose em associação com a pediculose e a soropositividade para FIV/FeLV, cujos tratamentos implementados obtiveram resultados parciais. Em virtude da persistência do prurido e do surgimento de novas lesões de pele, houve a necessidade da realização de nova investigação, que revelou a presença de Demodex cati.

A associação de demodicose com FIV ou FeLV foi descrita por outros autores [2,4]. Casos de felinos com esporotricose co-infectado por FIV e/ou FeLV também foram descritos [10]. O paciente em questão apre-

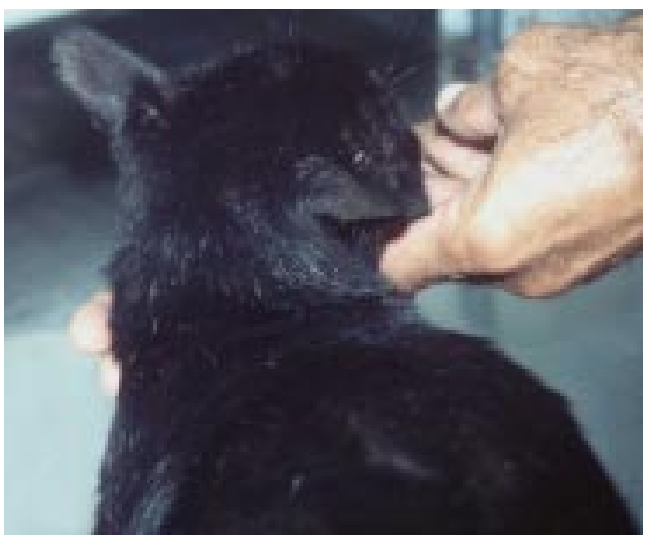

Figura 5. Ausência de lesões cutâneas ativas nas regiões cefálica e cervical dorsais do gato. 
sentava ELISA positivo para FIV e FeLV, demodicose, esporotricose e pediculose, não sendo encontrado na literatura outro relato de tal associação.

A co-infecção com FIV e FeLV pode ter favorecido a associação de doenças e agravado o quadro dermatológico do paciente. A raridade da associação de infecções causadas por diferentes agentes retardou a realização do diagnóstico definitivo. O paciente obteve a cura clínica das ectoparasitoses e, posteriormente da esporotricose, apesar da co-infecção viral e da adesão parcial do proprietário ao tratamento, evidenciada pela não observância das medidas de controle propostas, pelo não comparecimento às revisões solicitadas e pela irregularidade na administração dos fármacos.

\section{REFERÊNCIAS}

1 Barros M.B., Schubach A.O., Valle A.C., Gutierrez Galhardo M.C., Conceição-Silva F., Schubach T.M., Rei, R.S., Wanke B. \& Marzochi K.B. 2004. Cat-transmitted sporotrichosis epidemic in Rio de Janeiro, Brazil: description of a series of cases. Clinical Infectious Diseases. 38: 529-35.

2 Chalmers S., Schick R.O. \& Jeffers J. 1989. Demodicosis in two cats seropositive for FIV. Journal of American Veterinary Medical Association. 194: 256-257.

3 Conroy J.D., Healey M.C. \& Bane A.G. 1982. New Demodex sp infesting a cat: a case report. Journal of the American Animal Hospital Association. 18: 405-407.

4 Cowan L.A. \& Campbell K. 1988. Generalized demodicosis in a cat responsive to amitraz. Journal of American Veterinary Medical Association 192: 1442-1444.

5 Desch Jr. C.E. \& Stewart T.B. 1999. Demodex gatoi: New species of hair follicle mite (Acari: Demodecidae) from the domestic cat (Carnivora: Felidae). Journal of Medical Entomology. 36: 167-170.

6 Kwochka K.W. 1994. Demodicosis. In: Griffin C.E., Kwochka K.W. \& MacDonald J.M. (Eds). Enfermedades dermatologicas del perro y el gato: Ciencia y arte de la terapeutica. 1ed. Buenos Aires: Intermedica, pp.85-100.

7 Paterson S. 2000. Parasitic skin diseases. In: Skin diseases of the cat. Oxford: Blackwell Science, pp.69-99.

8 Rippon J. 1988. Sporotrichosis. In: Medical Mycology - The pathogenic fungi and the pathogenic actinomycetes. Philadelphia: W. B. Saunders Company, pp.325-352.

9 Schubach T. M. 2004. Estudo clínico, laboratorial e epidemiológico da esporotricose felina na região metropolitana do Rio de Janeiro. 68f. Rio de Janeiro, RJ. Tese (Doutorado em Biologia Parasitária). Instituto Oswaldo Cruz.

10 Schubach T. M.P., Schubach A., Okamoto T., Barros M. B.L., Figueiredo F. B., Cuzzi T., Fialho-Monteiro P. C., Reis R. S., Perez M.A. \& Wanke B. 2004. Feline sporotrichosis epidemic in the Metropolitan area of Rio de Janeiro - Clinical presentation and treatment of 347 cats (1998-2001). Journal of American Veterinary Medical Association. 224: 1623 -1629.

11 Scott D.W., Miller W.H. \& Griffin C.E. 1996. Doenças fúngicas da pele. In: Miller \& Kirk - Dermatologia de pequenos animais. 5.ed. Rio de Janeiro: Interlivros, pp.301-369.

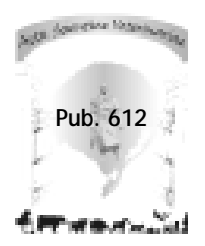

